\title{
DIZE-ME O QUE ENSINAS, QUE EU TE DIREI O QUE ÉS (E QUANTO VALES): A CONCEPÇÃO DE DOCENTE NO SARESP
}

\author{
DIME LO QUE ENSEÑAS, LO QUE LE DIGO LO \\ QUE ERES (Y USTED COSTO): LA ENSEÑANZA \\ DEL PROFESOR IN SARESP
}

\author{
TELL ME WHAT TEACHES, WHAT I WILL TELL YOU \\ WHAT YOU ARE (AND HOW MUCH ARE YOU): \\ THE TEACHER'S CONCEPTION IN SARESP
}

\author{
Nayane Moreno Perea ${ }^{1}$ \\ GÉsSICA PRISCILA RAMOS ${ }^{\mathrm{I}}$
}

Resumo O SARESP é um sistema de avaliação em larga escala, implementado pela Secretaria de Estado da Educação de São Paulo (SEE-SP), cuja intenção é avaliar e atuar na qualidade do ensino ofere cido nas escolas da rede pública de ensino paulista. Por intermédio de políticas agregadas a ele, bem como, das mudanças efetivadas em sua estrutura e funcionamento desde a sua criação em 1996, o SARESP vem a cada dia mais exercendo forte influência na organização escolar, e, principalmente, nas práticas pedagógicas desenvolvidas pelos professores em sala de aula. Assim, o objetivo deste artigo é compreender a concepção de professor presente no SARESP mediante a análise do seu contexto e da sua estrutura e funcionamento, dando enfoque aos aspectos que impactam direta ou indiretamente no trabalho docente. Para atender a esse objetivo, foi utilizada como procedimento metodológico a análise bibliográfica e documental. Verificou-se que o professor é aquele que, em detrimento da própria docência, vai ser mensurado e valorizado por sua destreza em reproduzir no aluno o que foi preconizado pelo SARESP. Há uma inversão de papéis: a escola, por seus professores, passa a ensinar aquilo que é avaliado pelo SARESP, ao invés de o SARESP considerar aquilo que a escola, por intermédio de seu professor, ensina. Palavras-chave: SARESP; Política Educacional; Professor.

Universidade Federal de São Carlos (UFSCAR), São Carlos/SP - Brasil 
Abstract SARESP is a large-scale evaluation system implemented by the State Department of Education of São Paulo (SEE-SP), whose intention is to evaluate and act on the quality of the teaching offered in the public schools of São Paulo. Through policies added to it, as well, as changes in its structure and functioning since its creation in 1996, SARESP is increasingly exerting a strong influence on school organization, and especially on the pedagogical practices developed by teachers in the classroom. Thus, the purpose of this article is to understand the conception of the teacher present in the SARESP by analyzing its context and its structure and functioning, focusing on aspects that directly or indirectly impact on teaching work. To meet this objective, bibliographic and documentary analysis was used as methodological procedure. It was verified that the teacher is the one who, in detriment of the teaching itself, will be measured and valued for his skill in reproducing in the student what was recommended by the SARESP. There is a reversal of roles: the school, by its teachers, teaches what is evaluated by SARESP, instead of SARESP evaluating what the school teaches through the teacher.

Key-words: SARESP; Educational Policy; Teacher.

RESUmen El SARESP es un sistema de evaluación a gran escala implementado por la Secretaría de Estado de Educación de São Paulo (SEE-SP), cuya intención es evaluar y actuar en la calidad de la enseñanza ofrecida en las escuelas de la red pública de enseñanza paulista. A través de políticas agregadas a él, así como de los cambios efectivos en su estructura y funcionamiento desde su creación en 1996, el SARESP viene cada día más ejerciendo fuerte influencia en la organización escolar, y principalmente en las prácticas pedagógicas desarrolladas por los profesores en sala de aula. Así, el objetivo de este artículo es comprender la concepción de profesor presente en el SARESP mediante el análisis de su contexto y de su estructura y funcionamiento, dando enfoque a los aspectos que impactan directa o indirectamente en el trabajo docente. Para atender a ese objetivo, se utilizó como procedimiento metodológico el análisis bibliográfico y documental. Se verificó que el profesor es aquel que, en detrimento de la propia docencia, va a ser medido y valorado por su destreza en reproducir en el alumno lo que fue preconizado por el SARESP. Hay una inversión de roles: la escuela, por sus profesores, pasa a enseñar lo que es evaluado por el SARESP, en lugar de que el SARESP evalúe lo que la escuela, a través de su profesor, enseña.

Palabras clave: SARESP; Política Educativa; Profesor.

\section{INTRODUÇÃo}

O SARESP é o Sistema de Avaliação do Rendimento Escolar do Estado de São Paulo, incumbido pela avaliação externa em larga escala das escolas paulistas de Ensino Fundamental (EF) e do Ensino Médio (EM). Foi implementado, em 1996, na gestão de Mario Covas, por meio da Secretaria de Estado da Educação de São Paulo (SEE), tendo como objetivo produzir dados para subsidiar a gestão e a política educacional paulista. Ampliando esse seu escopo, desde 2008, os resultados do SARESP também integram o Índice de 
Desenvolvimento da Educação do Estado de São Paulo (IDESP), cuja função declarada é fornecer, para cada escola da rede paulista de ensino, um diagnóstico de sua qualidade (SÃO PAULO, s/d). Para tanto, o SARESP é considerado um dos critérios centrais do IDESP, ${ }^{1}$ ao analisar a qualidade das escolas e o cumprimento das metas estabelecidas, balizando a definição sobre os profissionais a quem se deve atribuir (ou não) a bonificação pelos resultados alcançados.

A primeira edição do SARESP ocorreu em 1996 e, desde então, segundo Lammoglia e Bicudo (2012, p. 2), passou a ser realizado anualmente, com exceção dos anos 1999 e 2006. Contudo, ao longo de suas edições, o SARESP sofreu mudanças e reconfigurações referentes aos componentes curriculares bem como, aos anos/séries avaliados. Além dessas reconfigurações, esse sistema avaliativo passou por uma alteração importante em 2008, ao ser vinculado à Proposta Curricular do Estado de São Paulo (SÃO PAULO, 2008a).

Essa Proposta Curricular foi criada no referido ano, objetivando definir um currículo mínimo e comum para as escolas da rede pública de ensino paulista, ao fixar "metas de aprendizagens desejáveis em cada área, estabelecendo os conteúdos disciplinares a serem desenvolvidos em cada ano ou ciclo e o que se" esperava que os alunos fossem "capazes de realizar com esses conteúdos, expresso na forma de competências e habilidades claramente avaliáveis" (SÃO PAULO, 2009a, p. 11). Assim, a partir da Proposta Curricular foi elaborado o documento Matrizes de Referência para Avaliação (SÃO PAULO, 2009a) em 2009, que apresenta as bases conceituais da análise e os conteúdos a serem avaliados pelo SARESP (SÃO PAULO, 2009a, p. 14), buscando estabelecer uma correspondência entre o que se aprendia no dia a dia da sala de aula e o que seria considerado pelo SARESP.

Sob esse histórico e notadamente por influência das políticas agregadas a ele (Proposta Curricular do Estado de São Paulo, IDESP e Política de bonificação por resultados), o SARESP vem progressivamente exercendo forte influência na prática pedagógica docente. Destarte, diante da centralidade e da grande influência do SARESP na organização escolar e, principalmente, no trabalho docente, este artigo tem o objetivo de compreender a concepção de professor que fundamenta o SARESP, desde a sua implementação até o ano de 2015, com base em pesquisa bibliográfica e documental.

A fim de contemplar o objetivo central deste artigo, foram estabelecidas as seguintes categorias de análise: estrutura didático-pedagógica, conteúdo de ensino, papel do aluno e papel do professor na política educacional. Essas categorias serão analisadas por meio dos documentos legais e oficiais, sem se perder de vista que, para a análise desses documentos, é importante se ter clareza da distinção entre os seus objetivos oficiais proclamados, que indicam suas finalidades amplas e gerais, e os seus objetivos reais, que apontam os alvos concretos de sua ação (SAVIANI, 2008).

O documento Matrizes de Referência para a Avaliação (SÃO PAULO, 2009a) perpassará a análise de todas as categorias anunciadas. Ademais, o documento Sumário Executivo (SÃO PAULO, 2008b, 2009b, 2011b, 2012a, 2014a, 2015, 2016) será utilizado prioritariamente na abordagem da categoria "estrutura didático-pedagógica". O Relatório dos

\footnotetext{
Na aludida avaliação diagnóstica, para além do desempenho dos alunos no SARESP, o IDESP também considera o fluxo escolar como critério (SÃO PAULO, s/d).
} 
Estudos (SÃO PAULO, 2011a, 2011c, 2012b, 2014b) colaborará para o estudo das categorias "papel do aluno" e "papel do professor". Ao seu turno, o Manual de Orientação (SÃO PAULO, 2007) integrará também a análise da categoria "papel do professor".

\section{O CONTEXTO das POLÍticas de AVALIAÇão E O CASO PAULiSTa}

A reforma da educação dos anos 1990 conferiu papel de destaque à avaliação externa da educação dentro da política educacional brasileira, impactando na configuração da política de vários Estados, sobretudo de São Paulo. Assim, nota-se que o contexto de criação do SARESP não somente ultrapassa as fronteiras paulistas, como se constitui parte integrante de todo o movimento histórico nacional - e internacional - de reformas do período.

Essas reformas modificaram basicamente a relação estatal com a economia de mercado e com as políticas sociais, por meio de suas estratégias postas para as diferentes frentes de atuação do Estado brasileiro, que deveria tornar-se restrito quanto à sua intervenção na economia, permitindo o desenvolvimento livre do mercado, e mínimo, notadamente, no campo das políticas sociais. Segundo Ribeiro (2008), tais reformas representaram uma "mudança de paradigma", de um Estado, antes, interventor e executor, para um Estado avaliador e regulador das políticas sociais. Nessa acepção, a avaliação foi posta como instrumento de controle por parte do Estado, que passou a descentralizar-se em várias esferas, mormente no campo dos gastos públicos e das políticas sociais. Não por acaso, a reforma administrativa na educação foi "ganhando materialidade pela via da indução, do monitoramento, do controle e da avaliação" (FREITAS, 2004, p. 679), adquirindo, a partir dos anos 1990, grande importância na política educacional.

Destarte, por meio da avaliação dos resultados, tentava-se buscar eficiência, produtividade e qualidade da educação (SAVIANI, 2010), sem grandes dispêndios de ações e recursos por parte do Estado (RIBEIRO, 2008).

Enquanto a administração pública nacional implantava e difundia ações e estratégias com vistas à reforma estatal, a adoção de reformas coerentes a esta também foram adotadas no Estado de São Paulo (RAMOS, 2016). Assim, em 1995, o governador Mário Covas afirmava que as mudanças educacionais eram imprescindíveis para a reversão do quadro de extrema ineficiência gestacional, que atingia a SEE, como decorrência, sobretudo, do gigantismo da máquina burocrática e da falta de controle sobre o sistema de ensino (PINTO, 2011). Em face desse contexto, Covas estabeleceu a racionalização da gestão, a produtividade de recursos públicos e a melhoria na qualidade do ensino como diretrizes básicas para a realização das mudanças na educação paulista (RAMOS, 2016).

Balizado por esses alicerces, a atuação governamental buscava transformar a SEE em uma máquina administrativa leve e eficiente, "responsável pelo papel de planejador estratégico e não o de simples prestador de serviços" (SÃO PAULO, 1995), formulando uma nova política educacional. Desse modo, a reforma educacional paulista transitava entre o enxugamento da estrutura organizacional da SEE e a manutenção do controle decisório, estabelecendo em São Paulo um "modelo de descentralização tutelada" (RAMOS, 2016). Pretendia-se, assim, que o Estado, representado pela SEE, assumisse papel de regulador 
e avaliador do sistema educacional, relegando à escola e à sociedade o papel operativo e fiscalizador (RAMOS, 2016).

Nesse propósito, recorreu-se à implantação de uma série de estratégias, como: a desconcentração e descentralização de recursos e competências operacionais; estabelecimento de parcerias com escolas e sociedade para a prestação dos serviços educacionais; aumento da autonomia administrativa, financeira e pedagógica das escolas; implantação de um sistema de informatização dos dados educacionais; instituição de mecanismos de avaliação dos resultados (RAMOS, 2016), entre outras. Tais estratégias conduziram à criação de várias políticas e programas educacionais correspondentes aos ensejos da reforma, entre os quais se atribui grande destaque ao SARESP (PINTO, 2011).

O SARESP pretendia monitorar e acompanhar os resultados da qualidade da educação paulista nessa nova lógica, servindo como mecanismo de controle da educação paulista pelo Estado. Pode-se afirmar, então, que o SARESP não somente contribuiu para a formação de uma cultura avaliativa no Estado de São Paulo, como também serviu - articulado a outras medidas - como mecanismo de tutela.

\section{O PROFESSOR No SARESP}

A fim de se compreender a concepção de professor presente no SARESP, este artigo estabeleceu as seguintes categorias de análise: estrutura didático-pedagógica, conteúdo de ensino, papel do aluno e papel do professor na política educacional.

A categoria "estrutura didático-pedagógica" abrange o formato da avaliação do SARESP, ou seja, o modo pelo qual o referido sistema organiza a análise estadual paulista em termos pedagógicos. Essa análise perpassa pelo estudo das questões da avaliação, tendo em vista que, por meio delas, o SARESP imprime sua estrutura didático-pedagógica nas provas. Desse modo, várias perspectivas de análise das questões tornam-se relevantes, entre as quais se destacam: a definição de sua matéria; a elaboração e a organização das questões; a forma de resposta; a aferição em parâmetros avaliativos.

É a partir da Proposta Curricular do Estado de São Paulo (SÃO PAULO, 2008a) que a matriz de referência do SARESP (SÃO PAULO, 2009a) passou a indicar as competências e habilidades de língua portuguesa, matemática, ciências humanas e ciências da natureza para cada ano/série avaliado. Essas competências e habilidades apresentam-se em dois momentos nas "questões" da prova: quando balizam a formulação das questões e quando funcionam como parâmetros de respostas, pois o aluno, para respondê-las a contento, demandará o domínio das competências e habilidades.

Assim, a organização e a elaboração das questões do SARESP foram analisadas por meio do documento Sumário Executivo (SÃO PAULO, 2008b, 2009b, 2011b, 2012a, 2014a, 2015, 2016), a partir da edição de 2008 - edição em que as principais medidas técnicas e metodológicas adotadas já estavam vigentes -, salvo a edição de 2012, que não dispôs do aludido documento.

A matriz de referência (SÃO PAULO, 2009a) indica as matérias a serem contempladas e inseridas nas questões da avaliação, de modo que, compreendido isso, passa-se à sua 
elaboração e organização. Não obstante as diferenças entre as edições do SARESP, tentou-se identificar as constâncias na forma de elaboração de suas questões.

O modelo de prova empregado nas avaliações do SARESP, de acordo com São Paulo (2008b, 2009b, 2011b, 2012a, 2014a, 2015, 2016), abrange significamente o conjunto de habilidades e competências previsto na matriz de referência. Os itens avaliados orbitam as competências e habilidades de forma combinada, agrupando-as em cadernos de provas para cada ano e componente curricular avaliado (língua portuguesa, matemática, ciências humanas ou ciências da natureza). Destarte, as áreas do conhecimento não se entrelaçam na formulação das questões nem das respostas, não demandando associações interdisciplinares dos alunos para compreendê-las e respondê-las.

O quadro a seguir contém as informações sobre a composição das provas nas edições de 2008 a 2015, as quais evidenciam o modo de seleção e elaboração das questões.

Quadro 1 - Composição das provas nas edições de 2008 a 2015

\begin{tabular}{|c|c|}
\hline & Composição das provas nas edições de 2008-2015 \\
\hline 2008 & $\begin{array}{l}\text { - Itens comuns com o SAEB (Sistema Nacional de Avaliação da Educação Básica)/ } \\
\text { Prova Brasil; } \\
\text { - Itens elaborados e pré-testados pela Fundação VUNESP (Fundação para o } \\
\text { Vestibular da Universidade Estadual Paulista). }\end{array}$ \\
\hline 2009 & - Itens comuns com o SAEB/Prova Brasil. \\
\hline 2010 & $\begin{array}{l}\text { - Itens comuns com o SAEB/Prova Brasil; } \\
\text { - Itens selecionados de avaliações anteriores do SARESP. }\end{array}$ \\
\hline 2011 & $\begin{array}{l}\text { - Itens comuns com o SAEB/Prova Brasil; } \\
\text { - Itens selecionados de avaliações anteriores do SARESP; } \\
\text { - Itens selecionados de avaliações realizadas pela Secretaria de Educação do Estado } \\
\text { do Ceará, cedidos à SEE. }\end{array}$ \\
\hline 2012 & Não há informações. \\
\hline 2013 & $\begin{array}{l}\text { - Itens comuns com o SAEB/Prova Brasil; } \\
\text { - Itens selecionados de avaliações anteriores do SARESP; } \\
\text { - Itens elaborados e pré-testados pela Fundação VUNESP. }\end{array}$ \\
\hline 2014 & $\begin{array}{l}\text { - Itens comuns com o SAEB/prova Brasil; } \\
\text { - Itens selecionados de avaliações anteriores do SARESP; } \\
\text { - Itens elaborados e pré-testados pela Fundação VUNESP. }\end{array}$ \\
\hline 2015 & $\begin{array}{l}\text { - Itens selecionados de edições anteriores do SARESP; } \\
\text { - Itens de resposta aberta de Língua Portuguesa e Matemática, para o } 3^{\circ} \text {. ano do } \\
\text { Ensino Fundamental, elaborados por especialistas contratados pela VUNESP. }\end{array}$ \\
\hline
\end{tabular}

Fonte: Produção das autoras. 
Os itens comuns com o SAEB e Prova Brasil são selecionados para compor as questões da quase totalidade das edições pesquisadas, com exceção de 2015. Essa seleção é justificada no sentido de assegurar a comparabilidade entre os resultados do SARESP com os resultados da avaliação nacional (SÃO PAULO, 2008b, 2009b, 2011b, 2012a, 2014a, 2015). São nomeados pelo documento como itens de ligação na medida em que "ligam" uma avaliação à outra. Outra constante é a seleção de itens das edições anteriores do SARESP, com exceção de 2008. A elaboração e os pré-testes de questões pela Fundação VUNESP também têm relevância nas provas do SARESP, salvo edições 2010 e 2011. Excepcionalmente em 2011, o SARESP utilizou também itens de avaliação concedidos pela Secretaria de Educação do Estado do Ceará.

Conforme análise do Sumário Executivo de 2008 a 2015 (SÃO PAULO, 2008b, 2009b, 2011b, 2012a, 2014a, 2015, 2016) observa-se que, apesar de variações de anos/ séries avaliados, há um padrão na forma de respostas das questões das provas SARESP: a) para os anos/séries iniciais do EF, há o predomínio de questões abertas nas áreas de língua portuguesa e matemática; b) para os anos/séries finais do EF e para o EM, há o predomínio de questões objetivas nas áreas de língua portuguesa, matemática, ciências humanas e ciências naturais - salvo a edição de 2015.

Ao longo da maioria dessas edições, as áreas de ciências humanas e ciências naturais foram preteridas em relação à língua portuguesa e matemática, na medida em que foram avaliadas e contempladas no SARESP em menor número de questões, com exceção do ano de 2008. Na edição de 2015, as referidas áreas sequer foram incluídas na avaliação, a qual se restringiu apenas à língua portuguesa e matemática. Isso significa que não se atribui o mesmo peso, e por consequência, a mesma importância das áreas de português e matemática às outras áreas de ciências humanas ou naturais.

As respostas dos alunos, abertas ou objetivas, são avaliadas e classificadas em três nuanças: Insuficiente, Suficiente e Avançado. Cada nuança é representada por um ou dois níveis de proficiência com suas respectivas descrições, conforme quadro a seguir: ${ }^{2}$

Quadro 2 - Descrição da classificação e do nível de proficiência do aluno

\begin{tabular}{|c|c|c|}
\hline Classificaçāo & $\begin{array}{l}\text { Nivel de } \\
\text { Proficiência }\end{array}$ & Descriçāo \\
\hline Insuficiente & $\begin{array}{l}\text { Abaixo do } \\
\text { Básico }\end{array}$ & $\begin{array}{l}\text { Os alunos, neste nível, demonstram domínio insuficiente dos conteúdos, das competências e das } \\
\text { habilidades desejáveis para o ano/série escolar em que se encontram. }\end{array}$ \\
\hline \multirow{2}{*}{ Suficiente } & Básico & $\begin{array}{l}\text { Os alunos, neste nível, demonstram domínio mínimo dos conteúdos, das competências e das habilidades, } \\
\text { mas possuem as estruturas necessárias para interagir com a proposta curricular no ano/série subsequente. }\end{array}$ \\
\hline & Adequado & $\begin{array}{l}\text { Os alunos, neste nivel, demonstram domínio pleno dos conteúdos, das competências e das } \\
\text { habilidades desejáveis para o ano/série escolar em que se encontram. }\end{array}$ \\
\hline Avançado & Avançado & $\begin{array}{l}\text { Os alunos, neste nível, demonstram conhecimentos e domínio dos conteúdos, das competências e } \\
\text { das habilidades acima do requerido no ano/série escolar em que se encontram. }\end{array}$ \\
\hline
\end{tabular}

ronte: sAU rAULU, $\angle U 10$, p. 4.

2 O quadro refere-se à edição de 2015, mas sua organização está sistematizada de forma similar nas demais edições investigadas nesse tópico. Foi transcrito a título de exemplo. 
Nota-se que os níveis de proficiência na escala do SARESP apresentam como parâmetro as expectativas de aprendizagem (conteúdos, competências e habilidades) previstas para cada ano/série avaliado na matriz de referência (SÃO PAULO, 2009a) e na Proposta Curricular do Estado de São Paulo (SÃO PAULO, 2008a). Nesse passo, o nível adequado é o padrão de desempenho almejado pelo SARESP (SÃO PAULO, 2015), haja vista que representa o pleno domínio dos conteúdos, competências e habilidades previstas. A partir dele, os outros níveis são estabelecidos: básico, que significa o domínio mínimo pelos alunos daquilo que fora previsto na matriz de referência e na referida proposta curricular, de modo que serão capazes de interagir com as aprendizagens esperadas para o ano escolar subsequente; avançado, que contempla o domínio acima do esperado; abaixo do básico, que, de maneira oposta, contempla a situação de domínio abaixo do esperado.

Esses quatro níveis de proficiência são quantificados em intervalos de pontuações a serem atingidos pelos alunos na avaliação nas respectivas áreas curriculares para o seu ano/ série escolar. Sendo assim, o aluno é enquadrado no nível de proficiência, cujo intervalo contemple a sua pontuação em cada caderno de prova do SARESP. A título de ilustração, tem-se o quadro a seguir com os níveis de proficiência de língua portuguesa em 2015:

Quadro 3 - Medida do nível de proficiência do aluno em língua portuguesa no ano de 2015

\begin{tabular}{|lccccc|}
$\begin{array}{c}\text { Nivel de } \\
\text { Proficiência }\end{array}$ & $3^{\circ} \mathrm{EF}$ & $5^{\circ} \mathrm{EF}$ & $7^{\circ} \mathrm{EF}$ & $9^{\circ} \mathrm{EF}$ & $3^{\mathrm{a}} \mathrm{EM}$ \\
\hline Abaixo do Básico & $<125$ & $<150$ & $<175$ & $<200$ & $<250$ \\
\hline Básico & $125 \mathrm{a}<175$ & $150 \mathrm{a}<200$ & $175 \mathrm{a}<225$ & $200 \mathrm{a}<275$ & $250 \mathrm{a}<300$ \\
\hline Adequado & $175 \mathrm{a}<225$ & $200 \mathrm{a}<250$ & $225 \mathrm{a}<275$ & $275 \mathrm{a}<325$ & $300 \mathrm{a}<375$ \\
\hline Avançado & $\geq 225$ & $\geq 250$ & $\geq 275$ & $\geq 325$ & $\geq 375$ \\
\hline
\end{tabular}

Fonte: SÃO PAULO, 2016, p. 5.

Assim, por exemplo, se o aluno do $3^{\circ}$. ano do EF atingiu, na área de língua portuguesa, 126 pontos na edição do SARESP de 2015, conforme o quadro 3, o aluno se enquadraria no nível básico, pois o respectivo intervalo de pontuação é igual ou superior a 125 e inferior a 175 .

Diante dessas análises, o formato de prova impresso ao SARESP revela-se, em sua totalidade, subordinado à Proposta Curricular do Estado de São Paulo (SÃO PAULO, 2008a) e, mais especificamente, ao seu recorte de conteúdos, competências e habilidades feito pela Matriz de referência de avaliação (SÃO PAULO, 2009a), na medida em que incidem em todo processo de formação da prova: ora como indicação, como maneira de resolução, ora como parâmetro avaliativo.

As questões são elaboradas e agrupadas de modo a abarcarem as competências e habilidades previstas para cada componente curricular e para cada ano/série avaliados. Os alunos, para responder às questões, discursiva ou objetivamente, devem acionar suas competências e habilidades desenvolvidas na escola, aplicando-as na situação de prova. Poste- 
riormente, o sistema de avaliação aferirá qual nível os alunos estão, tomando as competências e habilidades previstas como parâmetro.

Vê-se, desse modo, que os resultados esperados pelo SARESP reverberam o papel da escola na rede estadual paulista. A SEE, por meio da estrutura didático-pedagógica desse sistema de avaliação, imprime nas escolas e no professor o modelo de ensino pretensamente defendido: ensinar conteúdos de natureza meramente instrumental, isto é, capazes de se desdobrarem em competências e habilidade úteis. Cabe às escolas e aos docentes assegurarem os domínios de competências e habilidades previstas na Proposta Curricular e, ao SARESP, classificar esse domínio - em avançado, adequado, básico, abaixo do básico -, constatando o que a escola fez ou deixou de fazer.

Esse papel da escola, elucidado na intervenção do SARESP, torna-se perceptível, por exemplo, na descrição do nível básico, que traz que o aluno domina minimamente as competências e habilidades esperadas para aquele ano, mas que possui condições de acompanhar a Proposta Curricular prevista para o ano letivo subsequente. É o mesmo que se dissesse: "esse aluno pode prosseguir na escola, pois acompanhará as competências e habilidades previstas, pela Proposta Curricular, para o trabalho do próximo ano".

A categoria "conteúdo de ensino" busca compreender a concepção de conteúdo avaliado pelo SARESP e o modo pelo qual é inserido na prova. Como resultado da vinculação do SARESP à Proposta Curricular do Estado de São Paulo, o documento Matrizes de referência para a avaliação (SÃO PAULO, 2009a) é fundamental para a sua compreensão, pois apresenta as bases conceituais da matriz elaborada para a política de avaliação. A figura a seguir evidencia essas bases conceituais: conteúdo, habilidades, competências, matemática, língua portuguesa, ciências humanas, ciências da natureza, escala de proficiência, níveis de desempenho. Assim:

Figura 1- Bases conceituais e áreas de avaliação do SARESP

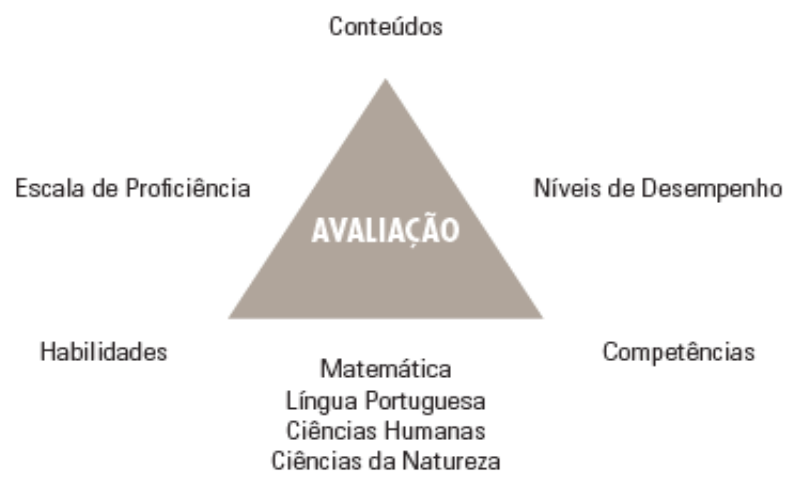

Fonte: SÃO PAULO, 2009a, p. 12. 
Nos vértices do triângulo, estão indicados os elementos de ensino e aprendizagem valorizados na matriz do SARESP (conteúdos, competências e habilidades) nas áreas da matemática, língua portuguesa, ciências humanas e ciências da natureza (base do triângulo). A aferição do domínio das habilidades e conteúdos pelos alunos nas respectivas áreas curriculares é sintetizada por intermédio da Escala de Proficiência (lado esquerdo do triângulo), que permite inferir os níveis de desempenho (lado direito do triângulo) das competências avaliadas. No centro do triângulo, encontra-se a própria avaliação, responsável pela movimentação de toda essa estrutura, com vistas à observação e promoção da aprendizagem efetiva dos alunos (SÃO PAULO, 2009a).

O documento, discorrendo sobre o lado direito do triângulo, afirma claramente que a relação entre conteúdos e competências representa o objetivo do SARESP:

\begin{abstract}
O lado direito da Figura 1 relaciona conteúdos e competências cuja função é o objetivo do Saresp, isto é, verificar se os professores estão ensinando (os conteúdos esperados para os anos escolares avaliados) e os alunos aprendendo (isto é, com que nível de proficiência dominam as competências avaliadas) (SÃO PAULO, 2009a, p. 12, grifos das autoras).
\end{abstract}

O domínio das competências, articulado às habilidades e aos conteúdos, representa não apenas o objetivo da política de avaliação externa como também significa, na perspectiva da SEE, o próprio compromisso das escolas públicas do Estado de São Paulo, na medida em que a avaliação tem o:

[...] propósito de caracterizar a missão da escola, entendida como um lugar e um tempo em que competências fundamentais ao conhecimento humano são aprendidas e valorizadas. Essas competências expressam a função emancipadora da escola, ao assumir que dominar competências é uma forma de garantir que houve aprendizagem efetiva dos alunos (SÃO PAULO, 2009a, p. 12, grifos das autoras).

Nesse sentido, a avaliação, além de observar o desempenho individual dos alunos, é capaz de, segundo o documento, verificar o quanto cada escola está podendo cumprir a sua função social, considerando que "[...] é efetuada em todo o Estado de São Paulo, e que as condições do exame, a estrutura e o funcionamento das escolas são equivalentes, ao menos na maioria dos casos [...]" (SÃO PAULO, 2009a, p. 12). Tal afirmação põe em xeque os questionários destinados aos pais, alunos e a outros agentes da educação (diretores, professores-coordenadores, professores), usados na avaliação do SARESP na maioria de suas edições, com o objetivo de identificar, caracterizar e analisar os fatores intra e extraescolares que interferem no desempenho escolar dos alunos e das unidades de ensino, bem como, de coletar informações sobre os perfis desses agentes (SÃO PAULO, 2007).

Destarte, o conteúdo de ensino, conforme se observou, é um dos elementos estruturantes da matriz de avaliação, ao lado das competências e habilidades. Em função disso, 
entender o conteúdo de ensino a ser avaliado no SARESP implica, a priori, compreender o seu vínculo com as competências e habilidades.

Os conteúdos, no SARESP, são expressos na forma de competências e habilidades a fim de serem mensuráveis, observáveis e avaliáveis (SÃO PAULO, 2009a). Na concepção da SEE (SÃO PAULO, 2009a), competências são modalidades estruturais da inteligência humana, as quais expressam um conjunto de ações e operações mentais que o sujeito utiliza para estabelecer relações com e entre os objetos, fenômenos e pessoas que deseja conhecer. Essas se traduzem, no âmbito do SARESP, na capacidade do aluno realizar e compreender, de diferentes formas, o problema proposto em situação de avaliação (SÃO PAULO, 2009a).

Paralelamente às competências, no momento de resolução do problema são exigidas e acionadas diversas habilidades, na medida em que representam "[...] o que é necessário que o aluno faça para dar conta e bem do que foi solicitado em cada questão ou tarefa" (SÃO PAULO, 2009a, p. 13). Pelas habilidades, assim, inferem-se o nível de domínio dos alunos nas competências avaliadas e vinculadas aos conteúdos das disciplinas e em cada série ou ano escolares envolvidos pelo SARESP. Nesse quadro, o documento conclui que as habilidades "[...] funcionam como indicadores ou descritores das aprendizagens que se espera os alunos terem realizado no período avaliado" (SÃO PAULO, 2009a, p. 13).

A figura 2, a seguir, consiste na organização sintética das competências avaliadas pelo SARESP sob a forma de agrupamentos:

Figura 2- Organização das competências avaliativas do SARESP em agrupamentos

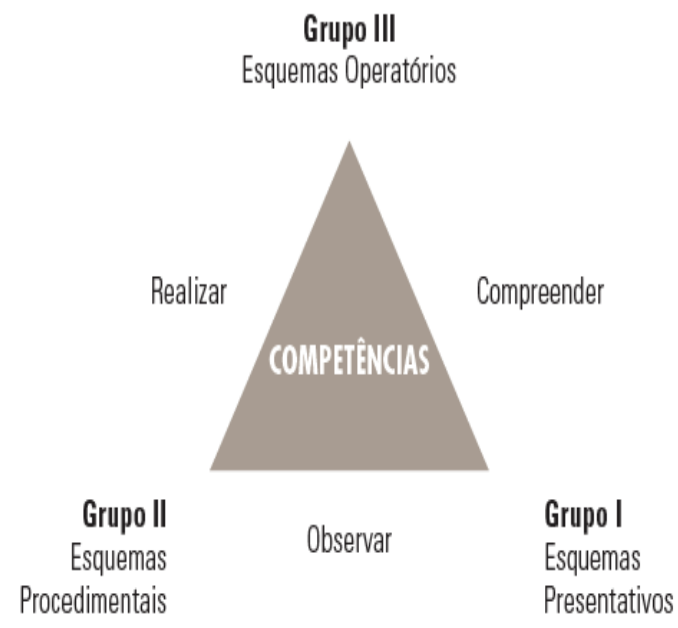

Fonte: SÃO PAULO, 2009a, p. 15.

Os vértices do triângulo indicam os três grupos de competências avaliados, com os seus respectivos esquemas cognitivos (Grupo I, Esquemas Presentativos; Grupo II, Esquemas Procedimentais; Grupo III, Esquemas Operatórios). Os lados dos triângulos correspondem às funções valorizadas na relação intergrupos. Isto é, observar é uma função 
importante para a relação entre o grupo I e II; realizar é preponderante para a relação entre o grupo II e III; compreender implica a relação entre o grupo III e I (SÃO PAULO, 2009a).

O Grupo I corresponde à capacidade de o aluno ler a questão ou problema proposto nas avaliações e, a partir disso, elaborar a sua resposta. Desse modo, considera-se o Grupo I como condição primeira para a elaboração da resposta pelo aluno frente à determinada questão. Envolve o uso de habilidades como ler, identificar, interpretar, descrever, localizar, diferenciar, constatar, reconhecer, relacionar, fazer correspondências etc. (SÃO PAULO, 2009a). O Grupo II refere-se à capacidade de o aluno realizar bem os procedimentos necessários para a resolução das questões propostas nas provas. Requer que o aluno proceda de forma coerente com os conteúdos avaliados e com o contexto das próprias questões. As habilidades envolvidas nesse grupo focam as atividades dos alunos (no quê e no como fazem) e implicam procedimentos como classificar, seriar, ordenar, (de)compor, calcular, fazer antecipações etc. (SÃO PAULO, 2009a). Por fim, o Grupo III corresponde às operações mentais mais complexas (pensamento proposicional e raciocínio hipotético-dedutivo), fundamentais para responder questões e solucionar problema. Essas operações ocorrem de maneira adequada ao nível de desenvolvimento cognitivo de cada aluno e envolvem habilidades como analisar, aplicar, fazer relações, tomar decisões, formular, propor, julgar, criticar, compreender, generalizar, deduzir, argumentar, supor etc. a partir do que cada sujeito já conhece, compreende, valoriza e domina (SÃO PAULO, 2009a). O conteúdo, em síntese, é aquele expresso em competências e habilidades, as quais permitem aos alunos observar (Grupo I), realizar (Grupo II) e compreender (Grupo III) um dado frente a uma situação-problema na escola, no SARESP e na vida, dando destaque àquelas relacionadas às capacidades leitoras e numéricas.

O conteúdo a ser avaliado no SARESP consiste em um recorte da Proposta Curricular do Estado de São Paulo (SÃO PAULO, 2008a), selecionando, entre todos os conteúdos previstos, aqueles vinculados às competências e habilidades mais gerais. Essas correspondem às expectativas de aprendizagens para os alunos nas disciplinas analisadas (SÃO PAULO, 2009a). Tem-se, desse modo, que:

[...] muitas competências e habilidades indicadas na Proposta Curricular, embora importantes para o desenvolvimento dos alunos e para o trabalho em sala de aula, não foram incluídas nas Matrizes, pois não são passíveis de ser avaliadas em instrumentos formais de provas realizadas em larga escala, como é o SARESP (SÃO PAULO, 2009a, p. 20).

Entretanto, a despeito dessa não abrangência de todos os conteúdos fundamentais do currículo, o SARESP, contraditoriamente, faz duas afirmações. A primeira, que as habilidades acionadas na avaliação, se bem avaliadas, "[...] evidenciarão o quadro real do efetivo desenvolvimento dos alunos ao tempo de realização da prova" (SÃO PAULO, 2009a, p. 14). A segunda, que as expectativas de aprendizagens correspondentes às habilidades "[...] representam o que se objetiva que os alunos desenvolvam em relação à proposta curricular" (SÃO PAULO, 2009a, p. 14). 
A contradição repousa na abrangência maior dos conteúdos, pois, se o SARESP não avalia todos os conteúdos presentes na Proposta Curricular, significa que essa é mais abrangente e completa no que tange aos conteúdos e às aprendizagens. Desse modo, seria ilógico e conflituoso considerar que os conteúdos exigidos pelo SARESP representam o quadro efetivo de aprendizagem do aluno bem como o objetivo da própria proposta, visto que deixa de lado importantes conteúdos. Por essas afirmações, a SEE parece confundir qual instrumento e política está atuando como referência para qual, ao preponderar o SARESP sobre a Proposta Curricular, isto é, acerca do currículo fixado para as escolas.

A SEE afirma ser o domínio das competências e habilidades a função social e emancipadora da escola de São Paulo (SÃO PAULO, 2009a) e que este será aferido pelo SARESP. Essa função da escola, claramente assumida pela SEE e perpetuada pelo SARESP, desvaloriza grandes áreas do conhecimento (como: ciências da natureza e ciências humanas) e desvaloriza conteúdos cuja natureza abstrata e intelectual não permite a redução em competências e habilidades práticas concretas. Por isso, é possível questionar-se a função de escola e de ensino defendido pela política educacional do Estado de São Paulo, por intermédio do SARESP.

A categoria "papel do aluno" perpassa indiretamente os documentos oficiais referentes ao SARESP, principalmente as Matrizes de referência da avaliação (SÃO PAULO, 2009a), ao tratar das aprendizagens, e o Relatório dos estudos ${ }^{3}$ (SÃO PAULO, 2011a, 2011c, 2012b, 2014b), ao abordar a caracterização dos alunos.

A partir da análise do documento Matrizes de referência (SÃO PAULO, 2009a) tangente à estrutura didático-pedagógico e aos conteúdos de ensino do SARESP, inferiu-se que o aluno é o sujeito capaz de observar (grupo I), realizar (grupo II) e compreender (grupo III) frente aos problemas propostos na avaliação, acionando competências e habilidades essenciais num nível padrão de proficiência. Quer dizer, a SEE espera que os alunos dominem as competências e habilidades elencadas no currículo, por meio do trabalho pedagógico cotidiano, de modo que saibam aplicá-las no SARESP. Não necessária e efetivamente, espera-se que o aluno aprenda conteúdos e conhecimentos. Apesar de o documento mencionar, ainda que raramente, o aluno como sujeito de conhecimento, vê-se que, na verdade, ao supervalorizar competências e habilidades, trata-o sumariamente como sujeito de competências.

A categoria "papel do professor" é central neste artigo, uma vez que se encaixa diretamente à sua finalidade de compreender a concepção do professor presente no SARESP.

Em primeira instância, o professor da rede pública de ensino do Estado de São Paulo tem explicitamente o papel de aplicador do SARESP. Segundo o documento Manual de Orientação (SÃO PAULO, 2007), a aplicação da avaliação dos primeiros anos/séries é realizada pelos próprios professores na escola, mas em turmas diferentes daquelas que

3 O Relatório dos Estudos sistematiza as principais informações coletadas por meio dos questionários respondidos pela rede de ensino estadual de São Paulo. Geralmente, divide-se em quatro seções, cada uma tratando respectivamente dos alunos; pais; professores e dos fatores associados ao desempenho dos alunos de determinada edição do SARESP. 
lecionam. Nos demais anos/séries avaliados, a aplicação é feita pelos professores da rede estadual, desde que em escolas diferentes daquelas que trabalham e que, preferencialmente, lecionem disciplinas não integrantes da avaliação.

$\mathrm{Na}$ função de aplicador, as atribuições dos professores, conforme o documento (SÃO PAULO, 2007), resume-se em: participar de reunião de orientação promovida pelo diretor da escola em que leciona; comparecer, uma hora antes, ao local de aplicação das provas; assinar o Termo de Compromisso; informar os alunos sobre a finalidade educativa da avaliação; garantir condições adequadas durante a aplicação; aplicar as avaliações, seguindo as instruções do Manual do aplicador; preencher o relatório do aplicador, registrando, por exemplo, a presença de cada aluno participante e as possíveis ocorrências no decorrer da avaliação.

Paralelamente a esse papel, identificou-se outro papel do professor no SARESP, subliminarmente delimitado pela estruturação da própria política de avaliação, na qual se destaca a vinculação do SARESP à Proposta Curricular do Estado de São Paulo, ao IDESP e à Política de Bonificação.

A vinculação do SARESP à Proposta Curricular do Estado de São Paulo (SÃO PAULO, 2008a) solucionou, de acordo com Matrizes de referência de avaliação (SÃO PAULO, 2009a), o principal problema da organização do sistema de avaliação: "O que avaliar? Pergunta para a qual a resposta mais significativa só pode ser: Aquilo que o aluno deveria ter aprendido" (SÃO PAULO, 2009a, p. 8, grifos das autoras). Nesse sentido, isso equivaleria, de maneira indireta, àquilo que o professor deveria ter ensinado aos seus alunos. Essa vinculação permitiu corresponder os conteúdos mais gerais da Proposta Curricular às competências e habilidades avaliadas pelo SARESP.

O documento indica (SÃO PAULO, 2009a), em várias passagens, o desenvolvimento da Proposta Curricular como atribuição do professor da rede paulista de ensino, dando prioridade às competências e habilidades delimitadas no SARESP. A título de demonstração, lê-se:

[...] a especificação das habilidades na matriz apresenta importantes mecanismos para que ele possa acompanhar o desenvolvimento dos alunos de sua turma em relação a sua proposta de trabalho, tendo em vista o cumprimento da proposta curricular no ano letivo (SÃO PAULO, 2009a, p. 11, grifos das autoras).

Essa atribuição também é evidenciada no documento Relatório dos estudos (SÃO PAULO, 2011a, 2011c, 2012b, 2014b), no tangente ao questionário destinado aos professores da rede paulista. Entre outros aspectos, por meio do questionário, a SEE analisa o "grau" de cumprimento da proposta curricular pelos professores no decorrer do respectivo ano letivo. Traz-se, como exemplo, a análise feita para a edição do SARESP em 2013: 
Quadro 4 - Análise geral dos resultados do SARESP, em 2013

\begin{tabular}{|c|c|c|c|c|}
\hline $\begin{array}{l}\text { O desenvolvimento do Currículo do Estado de São } \\
\text { Paulo em 2013, na sua escola, foi: }\end{array}$ & $2^{\circ} \mathrm{EF}$ & $3^{\circ} \mathrm{EF}$ & $5^{\circ} \mathrm{EF}$ & Média \\
\hline Todo o programa & 16,7 & 14,9 & 12,8 & 14,8 \\
\hline Quase todo o programa (entre $80 \%$ e $90 \%$ ) & 71.6 & 72,3 & 72,1 & 72,0 \\
\hline Mais da metade (entre $60 \%$ e $70 \%$ ) & 10.9 & 11.6 & 13.5 & 12.0 \\
\hline Aproximadamente a metade & 0.6 & 0.9 & 1.3 & 0.9 \\
\hline Menos da metade do programa & 0.2 & 0,3 & 0.3 & 0,3 \\
\hline Total & 100,0 & 100,0 & 100,0 & 100,0 \\
\hline
\end{tabular}

Fonte: SÃO PAULO, 2014b, p. 125.

Nessa conjuntura currículo-avaliação, percebe-se que a política educacional paulista impinge ao professor a função de ensinar os conteúdos, as competências e habilidades aos alunos em conformidade com a Proposta Curricular (SÃO PAULO, 2008a), cujo domínio será aferido pelo SARESP. Dessa maneira, pretende-se que, por meio de seu trabalho pedagógico cotidiano, o professor não apenas ensine conforme a previsão curricular como também dedique mais atenção às competências e habilidades selecionadas e avaliadas pelo SARESP.

Ao lado disso, o papel docente é reforçado pelo atrelamento do SARESP ao IDESP e à Política de Bonificação por resultados. O IDESP fixa metas para as escolas da rede pública do Estado de São Paulo ano a ano, cujo cumprimento, após o atrelamento, é aferido pelos resultados do SARESP e pelo fluxo escolar (número de aprovação, reprovação e abandono). Por sua vez, a Política de Bonificação ${ }^{4}$ consiste numa prestação financeira de caráter eventual recebida pelos profissionais da SEE em efetivo exercício, de acordo com o cumprimento das metas previamente fixadas (SÃO PAULO, 2008c) pelo IDESP. Isso significa, em linhas gerais, que os professores recebem o bônus caso atinjam as metas definidas pelo IDESP, e, por conseguinte, bons resultados no SARESP. A contrário sensu, os professores deixam de recebê-lo caso atinjam baixos resultados no SARESP e, em razão disso, não atinjam as metas previstas, indicando o professor como principal responsável pelo fracasso dos alunos, que não aprenderam o que o SARESP esperava deles.

Se a vinculação currículo-avaliação, como se viu, incumbiu ao professor ensinar aquilo que o SARESP selecionou da Proposta Curricular do Estado de São Paulo (SÃO PAULO, 2008a) e os seus resultados remontam o efetivo ensino do professor e aprendizagem dos alunos, o atrelamento SARESP, IDESP e Política de Bonificação, de forma articulada,

4 A Política de Bonificação por resultados dos profissionais da educação em São Paulo foi instituída pela Lei Complementar $n^{\circ}$. 1.078, de 17 de dezembro de 2008. Desde 2008, por meio do IDESP, temos o atrelamento do SARESP a essa política de bonificação. Com a referida Lei, os critérios definidos para pagamento foram: o critério Metas individuais, considerando o IDESP alcançado na relação SARESP-fluxo escolar; e a Frequência. O primeiro foi colocado como regulador do direito de receber a bonificação. O segundo, como exigência para se receber o bônus, já que, sem a frequência mínima estipulada de $2 / 3$, mesmo que se alcançasse a meta proposta, não se teria o direito de receber o bônus. 
atribui responsabilidade aos professores frente aos resultados obtidos no SARESP. Isso porque, o possível fracasso dos alunos na avaliação significa que eles não aprenderam o que deveriam naquele determinado ano/série e, por conseguinte, que o professor não deu conta de ensinar o que deveria, culminando em não recebimento de bônus.

O papel do professor, presente subliminarmente na política avaliativa, não é apenas ensinar em conformidade com o currículo proposto à rede paulista, enfocando a seleção do SARESP, mas sim garantir bons resultados nessa avaliação, sob pena de irresponsabilidade profissional. Destarte, por intermédio dessas políticas educacionais, o SARESP impacta no cotidiano do trabalho pedagógico dos professores. Não por acaso, segundo Arcas (2010), vários professores realizam simulados e intensivos nos moldes do SARESP,

[...] levam as provas do Saresp para a sala de aula, aplicam os exercícios, elaboram atividades seguindo esse modelo, corrigem e analisam as redações, utilizando a estrutura de análise e correção proposta, incluem ou eliminam conteúdos do planejamento de ensino e de aulas conforme o que "cai" no Saresp (ARCAS, 2010, p. 485, grifos das autoras).

\section{O PROFESSOR NO SARESP: O QUE É E QUANTO VALE?}

Os estudos realizados até aqui permitem que se reflita de forma embasada sobre o objetivo central deste artigo: compreender a concepção de professor e trabalho docente veiculada pelo SARESP.

Assim, a partir da categoria "estrutura didático-pedagógica", percebeu-se que o formato de prova subordina-se às competências e habilidades selecionadas da Proposta Curricular do Estado de São Paulo (SÃO PAULO, 2008a) pela Matriz de referência de avaliação (SÃO PAULO, 2009a), na medida em que referenciam a elaboração das questões da prova, a resolução dos alunos, como também, a avaliação de seus resultados. A estrutura didático-pedagógica do SARESP, indiretamente, incumbe aos professores a assegurarem os domínios de competências e habilidades previstas na Proposta Curricular pelos alunos e, ao SARESP, classificar esse domínio - em avançado, adequado, básico, abaixo do básico -, constatando o que o professor fez ou deixou de fazer.

Pela categoria "conteúdo de ensino", evidenciaram-se que os conteúdos avaliados são expressos em competências e habilidades mais gerais, previamente selecionadas da Proposta Curricular do Estado de São Paulo (SÃO PAULO, 2008a) e organizadas em três grupos (Grupo I - observar; Grupo II - realizar; Grupo III - compreender). Segundo a SEE (SÃO PAULO, 2009a), o domínio dessas competências e habilidades, aferido pelo SARESP, permite avaliar se houve ou não aprendizagem efetiva dos alunos na escola. Significa dizer que o domínio das competências e habilidades representa simultaneamente as expectativas de ensino das escolas públicas do Estado de São Paulo e as expectativas de avaliação do SARESP. Possibilita-se, desse modo, que o SARESP verifique se os professores estão ensinando as competências e habilidades esperadas e os alunos as aprendendo. 
Com base na categoria "papel do aluno", compreendeu-se que o SARESP avalia em qual nível de proficiência os alunos dominam as competências e habilidades, classificando-os em adequado, avançado, básico ou abaixo do básico. O aluno que, no domínio das competências e habilidades, saiba acioná-las e aplicá-las nas questões do SARESP num nível padrão de proficiência, executa o seu papel na política avaliativa do Estado de São Paulo.

Pela categoria "papel do professor", identificou-se um papel explícito do professor da rede paulista de ensino como aplicador da prova SARESP aos alunos. Paralelamente, a estruturação da política de avaliação e suas vinculações à Proposta Curricular do Estado de São Paulo, ao IDESP e à Política de Bonificação atribuem implicitamente outro papel aos professores: ensinar em conformidade com o currículo proposto à rede paulista, enfocando prioritariamente na seleção de competências e habilidades feita pelo SARESP, a fim de garantir bons resultados na avaliação. Desse modo, terá cumprido a contento o seu trabalho como professor, sendo recompensado e "incentivado" com o pagamento de bônus. Esse papel acarreta ao professor responsabilidades imensas em face ao resultado galgado pelos alunos no SARESP: se positivo, o professor é recompensado por bonificação; em contrapartida, se negativo, o professor é hostilizado pela política estadual. Tal quadro, conforme Pinto (2011), leva muitos professores a trabalharem apenas em função do SARESP a fim de prepararem os alunos para essa avaliação.

Assim, por intermédio da estruturação do SARESP e de sua vinculação com outras políticas, a SEE mantém, ano a ano, o seu papel de reguladora e avaliadora da rede educacional do Estado de São Paulo, ao passo que relega coercitivamente ao professor o papel operativo, impactando no cotidiano de seu trabalho pedagógico. Nesse sentido, o professor configura-se como aquele profissional da educação que, alinhado aos objetivos da SEE, deve desempenhar as incumbências formalizadas verticalmente e transferidas por meio da política estadual de avaliação e seus contornos. Isto é, o professor é aquele que, em detrimento da própria docência, vai ser mensurado e valorizado por sua destreza em reproduzir no aluno o que foi preconizado pelo SARESP.

A vinculação currículo-avaliação, evidente na análise da estrutura didático-pedagógica e do conteúdo de ensino, permite o direcionamento docente para o ensino de conteúdos de natureza meramente instrumental, desdobráveis em competências e habilidades, pretensamente, selecionadas pelo SARESP. Incumbe ao professor o desenvolvimento da Proposta Curricular do Estado de São Paulo, no que tange às áreas de ensino e às competências e habilidades explicitadas na avaliação, esvaziando a sua função de planejamento autônomo do ensino, específica do ethos professor. Isso porque a vinculação avaliação-bonificação, manifesta no atrelamento do resultado dos SARESP ao IDESP e à Política de Bonificação, permite à SEE o controle e o enquadramento da prática pedagógica de sala de aula, pois: atribui o resultado alcançado pelos alunos ao bom ou mau desempenho docente, rendendo-lhe, meritoriamente, culpa ou bônus, estabelecendo-se como um jogo perverso de comandos, recompensas ou penalidades.

Os professores, diante do exposto, são concebidos como ponto estratégico de execução da educação e da política educacional projetada, pela SEE, para o Estado de São Paulo. 
Nesse passo, a concepção de professor presente no SARESP coincide com a própria função executória atribuída ao professor nesse sistema de avaliação.

Desse modo, a finalidade última da escola deixa de ser o real aprendizado dos alunos para ser o alcance dos resultados do SARESP (ARCAS, 2010). A escola, por seus professores, é constrangida a ensinar aquilo que será avaliado pelo SARESP, ao invés de o SARESP avaliar aquilo que a escola ensina. Nesse caso, apesar do bônus, perde a escola, perde o professor, perde o aluno, enfim, perde, em possibilidades, toda educação escolar paulista...

\section{REFERÊNCIAS}

ARCAS, P. H. Saresp e progressão continuada: implicações na avaliação escolar. Est. Aval. Educ. São Paulo, v. 21, n. 47, p. 473-488, set./dez. 2010.

FREITAS, D. N. T. Avaliação da Educação Básica e ação normativa federal. Cadernos de Pesquisa, v. 34, n. 123, p. 663-689, set./dez. 2004.

LAMMOGLIA, B.; BICUDO, M. A. V. Sistema Escolar e Avaliação no Estado de São Paulo - Brasil. In: 'Gestión Pedagógica y Política Educativa' III Congreso Ibero-Americano de Politica y Administración de la Educación, 2012, Zaragoza - Espanha. Anais do III Congreso Ibero-Americano de Politica y Administración de la Educación, 2012.

PINTO, M. A. R. Política pública e avaliação: o SARESP e seus impactos na prática profissional docente, 2011, 167s. Dissertação (Mestrado em Serviço Social) - Faculdade de Ciências Humanas e Sociais, UNESP, Franca, 2011.

RAMOS, G. P. Racionalidade e gerencialismo na política educacional paulista de 1995 a 2014: muito além das conjunturas. Ensaio: aval. pol. públ. Educ. Rio de Janeiro, v. 24, n. 92, p. 546-578, jul./set., 2016.

RIBEIRO, D. da S. Sistema de avaliação do rendimento escolar do Estado de São Paulo (SARESP): a educação a serviço do capitalismo, 2008, 227 p. Dissertação (Mestrado em Educação) - Faculdade de Educação, UNICAMP, Campinas, 2008.

SÃO PAULO. Secretaria de Estado da Educação. Comunicado SE, de 22 de março de 1995. Torna público a todos os integrantes dos Quadros do Magistério, de Apoio Escolar e da Secretaria da Educação, as principais diretrizes educacionais para o Estado de São Paulo, para o período de janeiro de 1995 a 31 de dezembro de 1998. Diário Oficial do Estado, São Paulo, Seção 1, p. 8-10, 23, mar. 1995.

SÃO PAULO. Secretaria de Estado da Educação. Manual de Orientação. São Paulo, 2007. $24 \mathrm{p}$.

SÃO PAULO. Secretaria de Estado da Educação. Proposta Curricular do Estado de São Paulo: documento de apresentação. São Paulo, 2008a. 36 p.

SÃO PAULO. Secretaria de Estado da Educação. Sumário Executivo do SARESP 2008. São Paulo, 2008b. 134 p. 
SÃO PAULO. Lei Complementar $\mathbf{n}^{\mathbf{0}}$. 1.078, de 17 de dezembro de 2008c. Institui Bonificação por Resultados - BR, no âmbito da Secretaria da Educação. Disponível em: $<$ http://www.al.sp.gov.br/repositorio/legislacao/lei.complementar/2008/lei.complementar-1078-17.12.2008.html>. Acesso em: 12 jun. 2016.

SÃO PAULO. Secretaria de Estado da Educação. Matrizes de referência para a avaliação: documento básico. São Paulo, 2009a. 174 p.

SÃO PAULO. Secretaria de Estado da Educação. Sumário Executivo do SARESP 2009. São Paulo, 2009b. 138 p.

SÃO PAULO. Secretaria de Estado da Educação. Relatório dos Estudos do SARESP 2009. São Paulo, 2011a. 205 p.

SÃO PAULO. Secretaria de Estado da Educação. Sumário Executivo do SARESP 2010. São Paulo, 2011b. 233 p.

SÃO PAULO. Secretaria de Estado da Educação. Relatório dos Estudos do SARESP 2010. São Paulo, 2011c. 296 p.

SÃO PAULO. Secretaria de Estado da Educação. Sumário Executivo do SARESP 2011. São Paulo, 2012a. 193 p.

SÃO PAULO. Secretaria de Estado da Educação. Relatório dos Estudos do SARESP 2011. SÃO PAULO, 2012b. 310 p.

SÃO PAULO. Secretaria de Estado da Educação. Sumário Executivo do SARESP 2013. São Paulo, 2014a. 166 p.

SÃO PAULO. Secretaria de Estado da Educação. Relatório dos Estudos do SARESP 2013. São Paulo, 2014b. 340 p.

SÃO PAULO. Secretaria de Estado da Educação. Sumário Executivo do SARESP 2014. São Paulo, 2015. 150 p.

SÃO PAULO. Secretaria de Estado da Educação. Sumário Executivo do SARESP 2015. São Paulo, 2016. 134 p.

SÃO PAULO. Secretaria de Estado da Educação. O que é o IDESP. Disponível em: $<$ http:// idesp.edunet.sp.gov.br/o_que_e.asp>. Acesso em: 8 ago. 2014.

SAVIANI, D. A nova lei da educação: trajetória, limites e perspectivas, 11. ed. Campinas: Autores Associados, 2008.

SAVIANI, D. Historia das ideias pedagógicas no Brasil, 3. ed. Campinas: Autores associados, 2010. 


\section{Dados dos Autores:}

\section{Nayane Moreno Perea}

Licenciatura em Pedagogia na Universidade Federal de São Carlos (UFSCar). Graduanda em Direito no UNICEP. Mestranda no Programa de Pós-graduação em Educação da UFSCar na linha de pesquisa Estado, Política e Formação Humana.

\section{Géssica Priscila Ramos}

Doutorado em Educação pela Universidade Federal de São Carlos (2008) e mestrado em Educação Escolar pela Universidade Estadual Paulista Júlio de Mesquita Filho (2003). Professora adjunta da Universidade Federal de São Carlos e integrande do Programa de Pós-Graduação em Educação da mesma instiuição. Experiencia na área de Educação, com ênfase em Educação Brasileira, atuando principalmente nos seguintes temas: política e gestão educacional, valorização docente, identidade da escola e do professor.

Submetido em: 28/08/2017

Aceito em: 24/11/2017 